\title{
Histological study of effects of storage duration and temperature on the rabbits blood cells
}

\author{
Ibrahim K. I. Ragab \\ AL-Azhar Faculty of Medicine in Assiut
}

\begin{abstract}
Introduction: The temperature of the blood and its components during storage or processing is a very important factor affecting hemolysis. During storage, leukocytes break down and release a number of chemicals and enzymes, that have been reported to lysis RBC. With increasing duration of storage, the change of RBC shape becomes permanent. RBCs from different species behave differently during storage. So, this study aimed to investigate the histological effects of storage duration and temperature on the rabbit blood cells.

Material and Methods: Blood samples from five adult male healthy rabbits were divided into (Group I) stored at $4 \dot{\mathrm{C}}$ for 12 and 48 hours, (Group II) at a room temperature of about 24 $\hat{\mathrm{C}}$ for 12 and 48 hours and (Group III) at $36 \dot{\mathrm{C}}$ for 12 and 48 hours. Blood films made and stained by Leishman's stain immediately as a control group (A), after 12 hours (B) and after 48 hours (C) from each group respectively and examined for any morphological changes. Leukocytes counted totally immediately as a control group (A), after 12 hours (B) and after 48 hours $(\mathbf{C})$ from each group respectively for detection of any histological changes.

Results: no morphological changes of red blood cells, leukocytes and platelets of group I was observed. The changes of mean of total leukocytic counts of group I were non significant. Changes in total leukocytic counts and morphology of red blood cells, leukocytes and platelets of groups II and III were observed. The morphological degenerative changes of group II involved red blood cells, neutrophils and platelets at 12 and 48 hours. The morphological degenerative changes of group III involved red blood cells and leukocytes at 12 and 48 hours. The mean of total leukocytic counts of group II was significantly decreased at 48 hours while the mean of total leukocytic counts of group III was significantly decreased at 12 and 48 hours.

Conclusion: blood samples from rabbits should be tested within 12 hours of collection if stored at a room temperature of about $24 \dot{\mathrm{C}}$. Where testing is to be delayed for more than 12 hours, samples should be refrigerated as soon as possible. Exposure of samples to heat in excess of $24 \dot{\mathrm{C}}$ should be avoided at all times.
\end{abstract}

\section{Introduction}

The temperature of the blood and components during storage or processing is a very important factor affecting hemolysis. The temperature greatly affects membrane deformability and therefore the stability of the membrane during processing. Such thermally damaged RBC's may be broken down during processing, centrifugation and separation of blood units into different components. Hemolysis of the red cells increases due to processing and during storage and is maximum during the first week. Adequate process control and proper storage facilities should be ensured to minimize the hemolysis of red cells during processing and storage (Sawant et al., 2007). During storage leukocytes break down and release a number of chemicals and enzymes such as hydrogen peroxide and proteases. These proteases released by leucocytes during storage have been reported to cause RBC lysis during storage (Heaton et al., 1994). There is substantial evidence from in vitro studies documenting the changes that RBCs undergo during storage (the so-called 'red cell storage lesion'). Red cell adenosine triphosphate decreases by $50 \%$ during storage and 2,3diphosphoglycerate (2,3-DPG) is not maintained beyond 10 days. These changes increase the affinity of haemoglobin for oxygen and shift the oxygen dissociation curve leftwards. Red cells also undergo marked morphological changes during storage. These begin immediately after collection and consist largely of echinocytic 
change (the RBCs develop finger-like projections and adopt a spiky appearance). This shape change is initially reversible but with increasing duration of storage it becomes permanent as the finger-like projections bud off to form microvesicles (approximately $25 \%$ of membrane phospholipid is lost during 42 days of storage). The net effect of these morphological changes is a decrease in red cell deformability. Such observations make it reasonable to suggest that transfusing RBCs that are both 2,3-DPG depleted and poorly deformable could be ineffective and/or harmful, but there is scanty evidence to support this. Animal studies are problematic, because interspecies differences in RBC metabolism and structure mean that RBCs from different species behave differently during storage. For example, a much-quoted study found that 28-day-old rat blood failed to improve systemic oxygen consumption in rats in contrast to fresh rat blood (Fitzgerald et al., 1997). Subsequent work has shown that rat $\mathrm{RBCs}$ deteriorate much more rapidly during storage than human RBCs and that after 28 days of storage, only 5\% remain viable (d'Almeida et al., 2000). Transfusion of aged stored blood is associated with many neutrophil proinflammatory effects. The mechanism of these effects remains to be elucidated. Matrix metalloproteinases (MMPs) represent a group of enzymes involved in the degradation of most components of the extracellular matrix (Delclaux et al., 1997). The biological activities of MMPs are regulated in part by a group of naturally occurring inhibitors known as tissue inhibitors of metalloproteinases (TIMPs). Tissue inhibitor of metalloproteinase 1, the inhibitor of MMP9, is released along with MMP-9 in most cell types (Corbel et al., 2000). Matrix metalloproteinase 9 increases the biological activity of precursors of interleukins 8 and 1. The MMP-9 enzymatic activity increased with the duration of blood storage (Van der Steen et al., 2000), (Schonbeck, et al., 1998). Matrix metalloproteinase 9 accumulated in an active form in stored blood (Paul C et al., 2006). Degenerative changes occur when blood is allowed to stand in the laboratory before films are made. These changes are not solely due to the presence of an anticoagulant for they also occur in defibrinated blood. Regardless of the anticoagulant, certain changes take place when blood is allowed to stand in vitro at room temperature $(18-25 \mathrm{C})$. The red cells start to swell, the leukocytes and platelet counts gradually fall. It is best to count leukocytes and especially platelets within 2 hours (Van Assendelft, et. al., 1988). Nucleated red cells disappear from the blood specimen within 1-2 days at room temperature. The advisability of making films as soon as possible has already been stressed (Goossens et. al., 1991). Some but not all neutrophils are affected; their nuclei may stain more homogeneously than in fresh blood, the nuclear lobes may become separated and the cytoplasmic margin may appear ragged or less well defined; small vacuoles appear in the cytoplasm. Some or many of the large mononuclears develop marked changes; small vacuoles appear in the cytoplasm and the nucleus undergoes irregular lobulation which may almost amount to disintegration. Some of the lymphocytes, too, undergo a similar type of change; a few vacuoles may be seen in the cytoplasm and the nucleus may undergo major budding so as to give rise to nuclei with two or three lobes. Other lymphocyte nuclei may stain more homogeneously than usual. The red cells (of normal blood at least) are little affected by standing for up to 6 hours at room temperature (18-25C). Longer periods lead to development of many or numerous projections from the surface of red cells and disc-sphere transformation. All the above changes are retarded but not abolished in blood kept at 4 C. Their occurrence underlines the importance of making films as soon as possible after withdrawal. But delay of up to 1-3 hours or so is certainly permissible. The practice of making films of blood before it is added to the anticoagulant is to be commended, especially when screening for lead toxicity, as the granules of punctuate basophilia may stain less obviously in anticoagulated blood. In fresh blood films, the platelets usually clump and it is less easy to estimate the platelet count from inspection of the films. Irrespective of anticoagulant, films made from blood which has been standing for not more than 1 hour at room temperature (18-25 C) are 
not easily distinguished from films made immediately after collection of the blood. By 3 hours changes may be discernible and by 12-18 hours these become striking (Dacie \& Lewis, 1995).

\section{Material and Methods}

Blood samples from five adult male healthy rabbits were divided into (Group I) stored at $4 \dot{\mathrm{C}}$ for 12 and 48 hours, (Group II) at a room temperature of about $24 \hat{\mathrm{C}}$ for 12 and 48 hours and (Group III) at $36 \dot{\mathrm{C}}$ for 12 and 48 hours. Blood films made and stained by Leishman's stain immediately as a control group (A), after 12 hours (B) and after 48 hours (C) from each group respectively and examined for any morphological changes. Leukocytes counted totally immediately as a control group (A), after 12 hours (B) and after 48 hours $(\mathbf{C})$ from each group respectively for detection of any histological changes. The histological slides examined for RBCs, leukocytes and blood platelets by magnification (oil immersion $\mathrm{x}$ 1000).

Statistical analysis: it was carried out on total leukocytic counts of different groups according to the standard statistical procedures and Student $(t)$ test to estimate the significance of results using Microsoft Excel 2000.

\section{Results}

\section{I-Group I:-}

No morphological changes of red blood cells, leukocytes and platelets was observed. Normal red cells or erythrocytes showed only slight variation in size and shape with rouleau appearance. The cells had areas of central pallor which may be up to a third of the diameter of the cell. The lymphocyte was the smallest WBC. It had large condensed nucleus with scanty bluish cytoplasm. The eosinophil had bilobed nucleus with many cytoplasmic granules. The neutrophil had basophilic segmented nucleus. The platelets were small anuclear fragments containing small purple-staining granules. The changes of total leukocytic counts of group I B $(7.05 \pm 0.08)$ and I C (7.05 \pm 0.09$)$ compared to control group (7.07 \pm 0.08$)$ were non significant (plate 1 , table 1, figure 1).

\section{II-Group II:-}

Morphological degenerative changes of red blood cells, neutrophils and platelets observed at 12 and 48 hours. The RBCs developed finger like projections and presented a spiky appearance. Neutrophil nuclei rounded up and formed a homogeneous round single mass. Platelets aggregates composed of a mixture of apparently intact platelets and degranulated pale grey platelets. The mean of total leukocytic counts of group II C (4.96 \pm 1.19) was significantly lower than control group $(7.07 \pm 0.08)$ but the changes of total leukocytic counts of group II B (7.05 \pm 0.08 ) were non significant (plate2, table2, figure 2).

\section{III-Group III:-}

Morphological degenerative changes of red blood cells and leukocytes observed at 12 and 48 hours. Early at 12 hours the central biconcave area of RBCs appeared slit like. Normal platelets were apparent. They were small anuclear fragments between the red cells containing small purple-staining granules. The RBCs developed finger like projections and presented a spiky appearance. At 48 hours red cells bud off vesicles and microspherocytes seen. The white cells disintegrated and weakly basophilic particles similar in size to platelets seen. The finger like projections of RBCs became more prominent. The mean of total leukocytes counts of group III B (5.54 \pm $1.38)$ and III C $(5.39 \pm 1.56)$ were significantly lower than control group (7.07 $\pm 0.08)$ (plate2, table3, figure3). 
Table (1): Mean of total leukocytic count in group I (Gr. Comp. = groups compared).

\begin{tabular}{|l|c|c|c|}
\hline & $\begin{array}{c}\text { Control I } \\
\text { A }\end{array}$ & After 12h. I B & $\begin{array}{c}\text { After 48 h.I } \\
\text { C }\end{array}$ \\
\hline Mean & 7.07 & 7.05 & 7.05 \\
\hline STDEV & 0.08 & 0.08 & 0.09 \\
\hline ST Err. & 0.02 & 0.02 & 0.02 \\
\hline Gr.Comp. & & I A:I B & I A:I C \\
\hline P-Value & & 0.09 & 0.06 \\
\hline
\end{tabular}

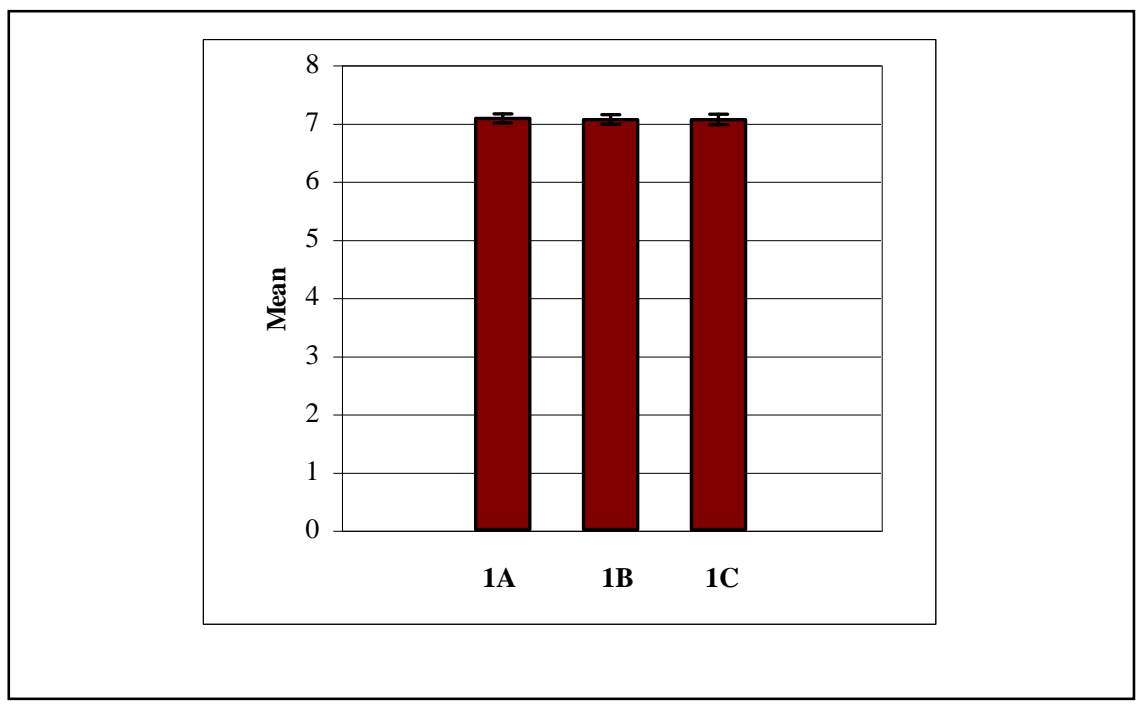

Figure (1): Mean of total leukocytic count in group I. The error bars represent the standard deviation.

Table (2): Mean of total leukocytic count in group II (Gr.Comp.= groups compared).

\begin{tabular}{|l|c|c|c|}
\hline & $\begin{array}{c}\text { control II } \\
\text { A }\end{array}$ & $\begin{array}{c}\text { After 12h. II } \\
\text { B }\end{array}$ & After 48 h.II C \\
\hline Mean & 7.07 & 7.05 & 4.96 \\
\hline STDEV & 0.08 & 0.08 & 1.19 \\
\hline ST Err. & 0.02 & 0.02 & 0.37 \\
\hline Gr.Comp. & & II A:II B & II A:II C \\
\hline P-Value & & 0.09 & 0.0001 \\
\hline
\end{tabular}




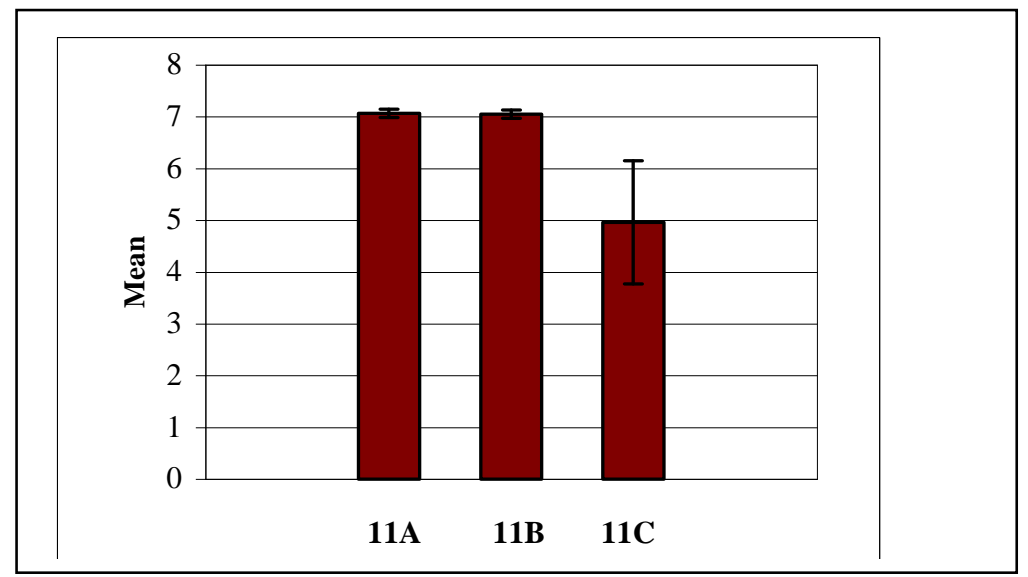

Figure (2): Mean of total leukocytic count in group II. The error bars represent the standard deviation.

Table (3): Mean of total leukocytic count in group III (Gr.Comp.= groups compared).

\begin{tabular}{|l|c|c|c|}
\hline & control III A & $\begin{array}{c}\text { After 12h. III } \\
\text { B }\end{array}$ & $\begin{array}{c}\text { After 48 h.III } \\
\text { C }\end{array}$ \\
\hline Mean & 7.07 & 5.54 & 5.39 \\
\hline STDEV & 0.08 & 1.38 & 1.56 \\
\hline ST Err. & 0.02 & 0.43 & 0.49 \\
\hline Gr.Comp. & & III A:III B & IIIA:III C \\
\hline P-Value & & 0.004 & 0.004 \\
\hline
\end{tabular}

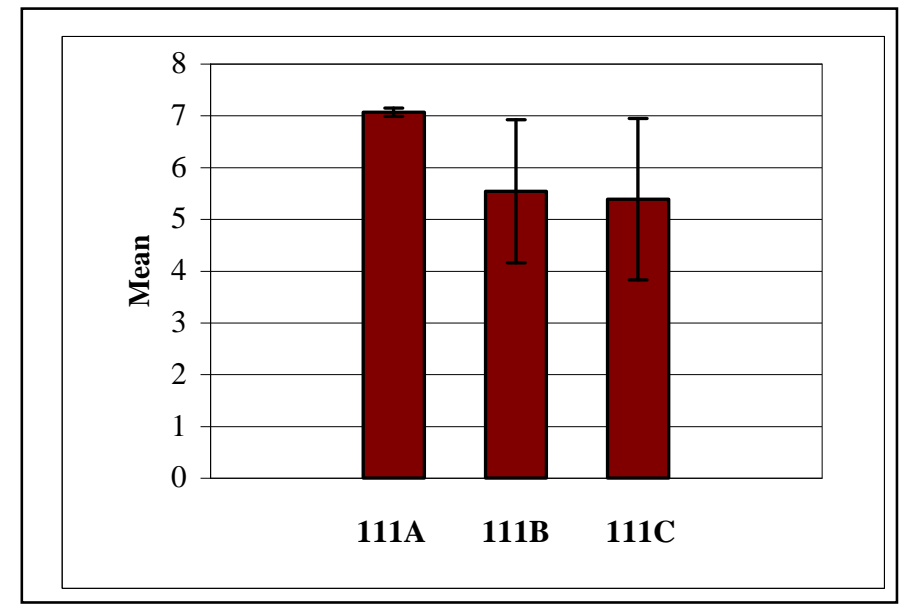

Figure (3): Mean of total leukocytic count in group III. The error bars represent the standard deviation. 


\section{Ibrahim K. I. Ragab}

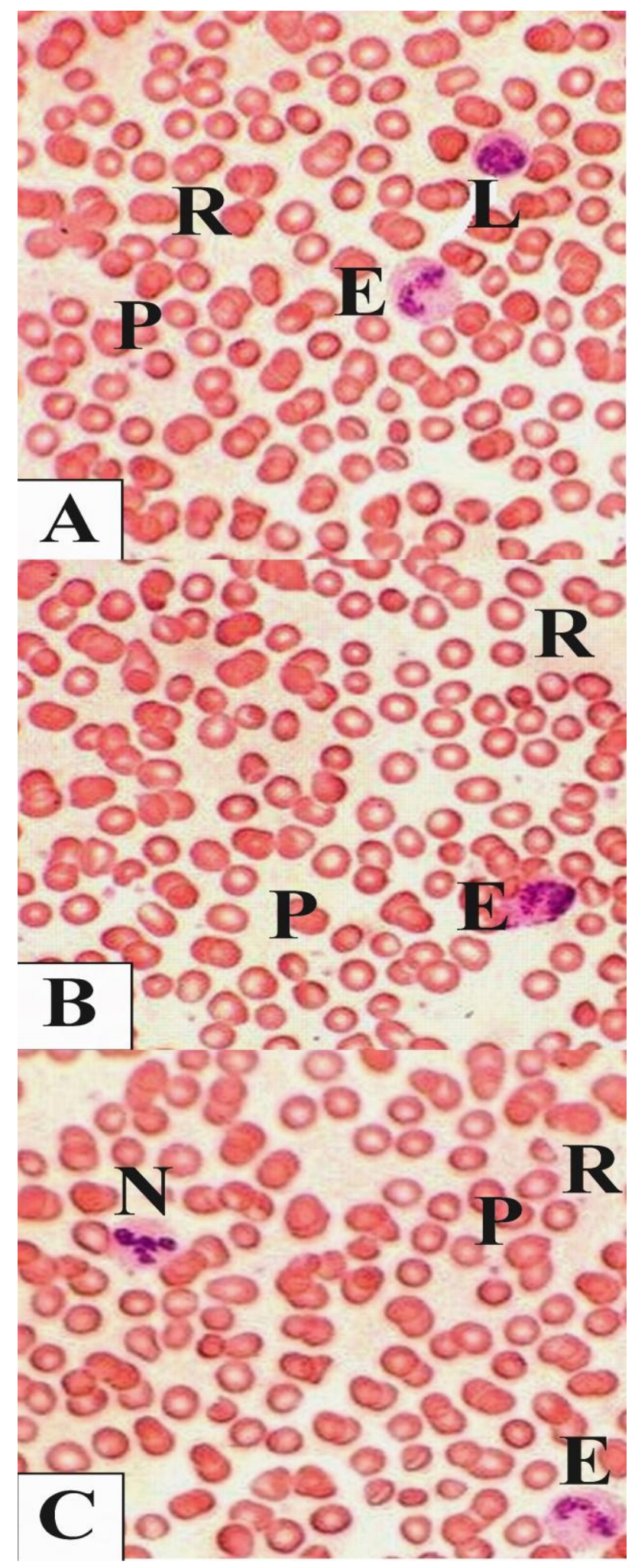

Plate 1:-(Leishman's stain, oil immersion x 1000), figure-A, B and C represent blood films from group-I A, I B and I C respectively. There is normal red cells $(\mathrm{R})$ showing only slight variation in size and shape with rouleau appearance. The cells had areas of central pallor which may be up to a third of the diameter of the cell. The lymphocyte (L) was the smallest WBC. It had large condensed nucleus with scanty bluish cytoplasm. The eosinophil (E) had bilobed nucleus with many cytoplasmic granules. The neutrophil $(\mathrm{N})$ had basophilic segmented nucleus. The platelets (P) were small anuclear fragments containing small purple-staining granules. 


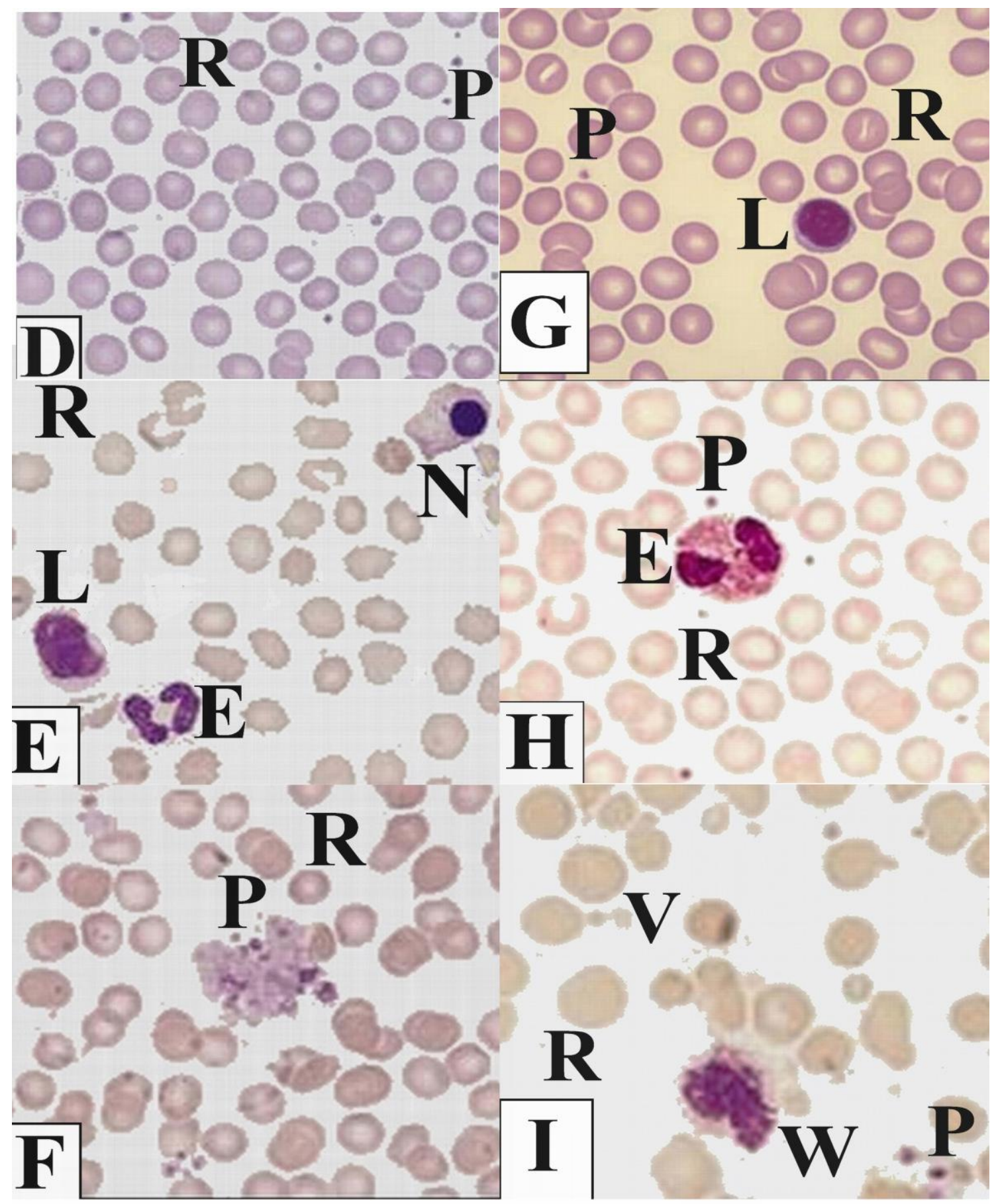

Plate 2:- (Leishman's stain, oil immersion $\mathrm{x} 1000$ ), on the left side, figure-D represent blood films from group-II B, figure-E and $\mathrm{F}$ represent blood films from group-II $\mathrm{C}$ respectively. There is degenerative changes of blood cells. The RBCs developed finger like projections and presented a spiky appearance. Neutrophil nuclei rounded up and formed a homogeneous round single mass. Platelets $(\mathrm{P})$ aggregates composed of a mixture of apparently intact platelets and degranulated pale grey platelets. On the right side, figure-G and $\mathrm{H}$ represent blood films from group-III B and figure-I represent blood films from group-III C respectively. There is degenerative changes of blood cells. Early the central biconcave area of RBCs appeared slit like. Normal platelets (P) were apparent. They were small anuclear fragments between the red cells containing small purple-staining granules. The RBCs developed finger like projections and presented a spiky appearance. At 48 hours the red cells bud off vesicles (V) and microspherocytes seen. White cells (W) disintegrated and weakly basophilic particles similar in size to platelets seen. The finger like projections of RBCs became more prominent. 


\section{Ibrahim K. I. Ragab}

\section{Discusion}

In this study the histological effects of storage duration and temperature on the rabbits blood cells were evaluated. In RBCs morphology, it was found that at $4 \mathrm{C}$ after 12 and 48 hours, only slight variations in shape and size with rouleau appearance. At $24 \mathrm{C}$ after 12 and 48 hours, RBCs developed finger like projections and presented a spiky appearance. At $36 \mathrm{C}$ after 12 hours the central biconcave area of RBCs appeared slit like. The RBCs developed finger like projections and presented a spiky appearance. At $36 \mathrm{C}$ after 48 hours, red cells bud off vesicles and microspherocytes seen. The slight variations in shape and size with rouleau appearance can be explained by decreased negative charges on the RBC membrane caused by increased concentrations of positivelycharged proteins in plasma (i.e., fibrinogen, immunoglobins) (Zipursky et al., 1983). The finger like projections and spiky appearance can be explained by changes occurring in the distribution of phosphoplipids in the RBC membrane because mature RBCs can not synthesize lipids, they rely on a continuous exchange of lipids between their membranes and plasma lipoproteins (Mary et al., 2004). The membrane phospholipids of RBCs were lost during storage (Fitzgerald et al., 1997) and red cell adenosine triphosphate decreased by $50 \%$ during storage and 2,3-

diphosphoglycerate (2,3-DPG) is not maintained beyond 10 days (McLellan et al., 2002). It can be also explained by the fact that leukocytes break down during storage at $36 \mathrm{C}$ after 48 hours and release a number of chemicals and enzymes such as hydrogen peroxide and proteases which have been reported to cause RBC lysis (Heaton et al., 1994). The formation of vesicles and microspherocytes seen can be explained by antibody binding to the RBC membrane, and subsequent removal of a portion of the membrane by a macrophage (Mary et al.,2004). In WBC counts, it was found that at $4 \mathrm{C}$ after 12 and 48 hours the changes were non significant. At $24 \mathrm{C}$ after 48 hours WBC counts were significantly decreased. At $36 \mathrm{C}$ after 12 hours, WBC counts were significantly decreased. These results were in consistent with Hume-Moir et al. study that evaluated blood samples from five wester grey Kangaroos which were stopred at $4 \mathrm{C}, 24 \mathrm{C}$ and $36 \mathrm{C}$. Each sample was analysed haematologically including WBC counts over a 5-day period. They have reported that blood samples maintained optimal stability at $4 \mathrm{C}$. At this temperature, the WBC counts remained essentially unchanged for the duration of the study, while samples stored at $36 \mathrm{C}$ and $24 \mathrm{C}$ showed significant decrease in WBC counts by 12 hours and 48 hours, respectively. The significant decrease of total leukocytic counts in group II and III may be due to the fact that many leukocytederived bioactive substances, such as lipid mediators, (Silliman et al., 1993 \& 1994) histamine, (Nielsen et al., 1996) and cytokines such as interleukins 1 and 8, accumulate over time in the stored blood which can lead to destruction of leukocytes (Kristiansson et al., 1996). In leukocytes morphology, it was found that at $4 \mathrm{C}$ after 12 and 48 hours no morphological changes of lymphocytes, eosinophils and neutrophils. At $24 \mathrm{C}$ after 48 hours, neutrophils nuclei rounded up and formed a homogeneous round single mass. At $36 \mathrm{C}$ after 48 hours white cells disintegrated and weakly basophilic particles similar in size to platelets seen. These results were not in consistent with Hume-Moir, et al.(1999) study who found evident disturbances in leukocyte morphology, to varying degrees, in all samples. The difference between the results of this study and the results of Hume-Moir may be due to the haematological characteristics of western grey Kangaroos (Macropus fuliginosus). The changes in leukocytes morphology in this study can be explained by the fact that heat act as a type of oxidative stress which can result in serious cell damage if the stress is massive or prolonged (Robert et al., 1993). Aged stored blood develop PMN (polymorphonuclear leucocyte) apoptosis, prolonging the functional lifespan of the PMN so that it may continue to respond to inflammatory mediators (Biffl et al., 1994). Stored blood delays PMNs apoptosis and primes endogenous PMNs for enhanced 
superoxide production and elastase release (Silliman et al., 1994), (Biffl, et al., 2001), (Biffl et al., 1999). In platelets morphology, it was found that at $4 \mathrm{C}$ after 12 and 48 hours there was no morphological changes. At $24 \mathrm{C}$ after 48 hours, platelets aggregates composed of a mixture of apparently intact platelets and degranulated pale grey platelets. At $36 \mathrm{C}$ after 12 and 48 hours normal platelets were apparent. They were small anuclear fragments between the red cells containing small purple-staining granules. Platelets aggregation can be explained by activation of the platelets by agonists (thrombin, collagen, ADP) which activates fibrinogen receptors and allow platelets to become cross-linked by fibrinogen. Strong aggregation responses require platelets to synthesize thromboxane A2, which requires the enzyme cyclooxygenase. Fibrin degradation products can inhibit platelet aggregation by blocking fibrinogen receptors. We can conclude that blood samples from rabbits should be tested within 12 hours of collection if stored at a room temperature of about $24 \mathrm{C}$. Where testing is to be delayed for than 12 hours, samples should be refrigerated as soon as possible. Exposure of samples to heat in excess of $24 \mathrm{C}$ should be avoided at all times.

\section{References}

1. Biffl WL, Moore EE, Offner PJ, Ciesla DJ, Gonzalez RJ, Silliman CC ( 2001): Plasma from aged stored red blood cells delays neutrophil apoptosis and primes for cytotoxicity: abrogation by post-storage washing but not pre-storage leukodepletion. J Trauma.,50:426-432.

2. Biffl WL, Moore EE, Offner PJ, et al. (1999): Blood transfusion independently delays neutrophil apoptosis in trauma patients [abstract]. Shock., 11(suppl):1.

3. Biffl WL, Moore EE, Moore FA, Carl VS, Kim FJ, Franciose RJ (1994): Interleukin-6 potentiates neutrophil priming with platelet-activating factor. Arch Surg. , 129:1131-1136.

4. Corbel M, Boichot E, Lagente V ( 2000) : Role of gelatinases MMP-2 and MMP-9 in tissue remodeling following acute lung injury. Braz J Med Biol Res., 33:749-754.

5. Dacie and Lewis, Practical Haematology, Eighth Edition, Chirchill Livingstone,
1995. d'Almeida MS, Jagger J, Duggan M, et al (2000) : A comparison of biochemical and functional alterations of rat and human erythrocytes stored in CPDA-1 for 29 days: implications for animal models of transfusion. Transfusion Med.,10: 291-303.

6. Delclaux C, d'Ortho MP, Delacourt C, et al. (1997): Gelatinases in epithelial lining fluid of patients with adult respiratory distress syndrome. Am. J. Physiol. .,272 : L442-L451.

7. Fitzgerald RD, Martin CM, Dietz GE, et al. (1997): Transfusing red blood cells stored in citrate phosphate dextrose adenine-1 for 28 days fails to improve tissue oxygenation in rats. Crit Care Med ., 25: 726-32.

8. Goossens, W., Van Duppen, V. and Verwilghen, R. H. (1991): K2- or K3EDTA: the anticoagulant of choice in routine haematology Clinical and Laboratory Haematology, 13: 291.

9. Heaton WA, Holmes S, Smith K, Brecher ME, Pineda A, AuBuchon JP, et al (1994): Effects of 3-5 $\log 10$ pre-storage leucocyte depletion on red cell storage and metabolism. Br J Hematol ., 87:363-8.

10. Hume-Moir, P. Clark, PBS Spencer.(1999): Effects of temperature and duration of sample storage on the haematological characteristics of western grey Kangaroos (Macropus fuliginosus). Australian Veterinary Journal 84 (4), 143147.

11. Kristiansson $M$, Soop $M$, Saraste $L$, Sundqvist KG.(1996): Cytokines in stored red blood cell concentrates: promoters of systemic inflammation and simulators of acute transfusion reactions? Acta Anaesthesiol Scand.., 40:496-501.

12. Mary M, Christopher, DVM, PhD, DACVP, DECVCP USA (2004): University of California, Davis, Department of Pathology, Microbiology, and Immunology School of Veterinary Medicine, Davis, CA, Interpretation of Red Blood Cell Morphology (Advanced Level). Red Blood Cell Morphology, 29 ${ }^{\text {th }}$ World Congress of the World Small Animal Veterinary Association,

13. McLellan, Walsh and McClellan (2002): Should we demand fresh red blood cells for perioperative and critically ill patients? British Journal of Anaesthesia, . 89, (4) 537-540.

14. Nielsen HJ, Edvardsen L, Vangsgaard K, Dybkjaer E, Skov PS (1996): Timedependent histamine release from stored human blood products. Br J Surg., 83:259262. 
15. Paul C. Frake, BS; Hadley E. Smith, MD; Lii-Fang Chen, MS; Walter L. Biffl, MD (2006) Prestorage Leukoreduction Prevents Accumulation of Matrix Metalloproteinase 9 in Stored Blood. Arch Surg. , 141:396-400.

16. Robert K., Murray, Daryl K, Granner, Peter A, Mayes, Victor W, Rodwell (1993): Harper's Biochemistry, a LANGE medical book, twenty-third edition.

17. Sawant RB, Jathar SK, Rajadhyaksha SB, Kadam PT: Red cell hemolysis during processing and storage. (2007): Asian Journal of transfusion sience, 1 (2):47-51.

18. Schonbeck U, Mach F, Libby P (1998): Generation of biologically active IL-1by matrix metalloproteinases: a novel caspase1 independent pathway of IL-1 processing. J Immunol., 161:3340-3346.

19. Silliman CC, Clay KL, Thurman GW, Johnson CA, Ambruso DR (1994): Partial characterization of lipids that develop during the routine storage of blood and prime the neutrophil NAPDH oxidase. J Lab Clin Med. 124:684-694.

20. Silliman CC, Johnson CA, Clay KL, Thurman GW, Ambruso DR (1993): Compounds biologically similar to platelet activating factor are present in stored blood components. Lipids, 28:415-418.

21. Van Assendelft, O. W. and Parvin, R. M. (1988). Specimen collection, handling and storage. In Quality Assurance in Haematology. Eds. S.M. Lewis and R. L. Verwilghen, p. 5. Bailliere Tindall, London.

22. Van den Steen PE, Proost P, Wuyts A, Van Damme J, Opdenakker G (2000): Neutrophil gelatinase B potentiates interleukin-8 tenfold by aminoterminal processing, whereas it degrades CTAP-III, PF-4, and GRO-and leaves RANTES and MCP-2 intact. Blood, 96:2673-2681.

23. Zipursky, A., Brown, E., Palko, J., and Brown, E.J. (1983): The erythrocyte differential count in newborn infants. American Journal of Pediatric Hematology and Oncology, 5: 45. 


\title{
دراسة هستولوجية لتأثيرات مدة ودرجة حرارة التخزين على خلايا الدم فى الأرنب
}

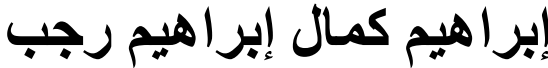 \\ كلية طب الأزهر أسيوط
}

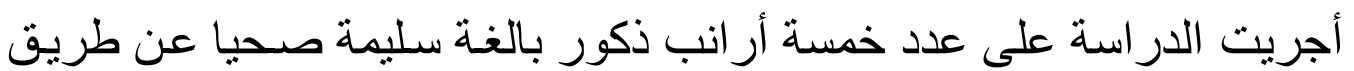

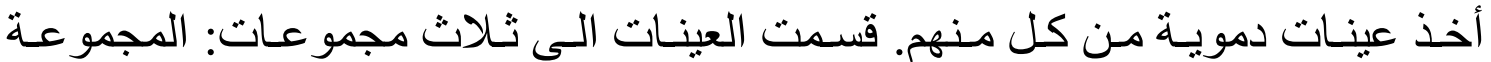

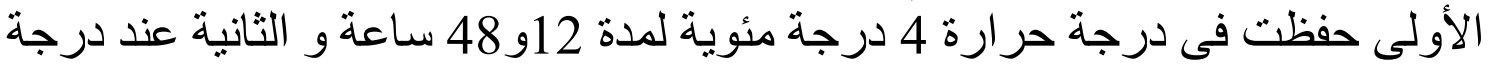

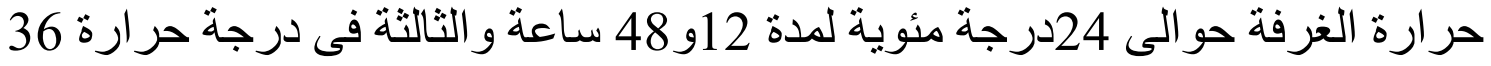

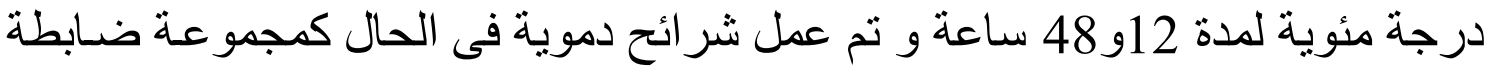

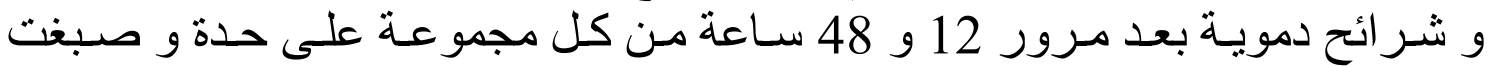

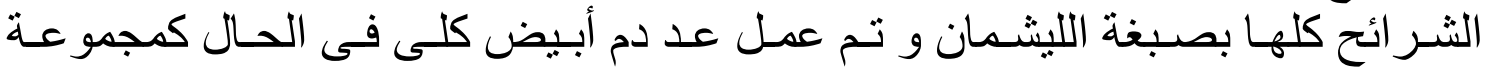

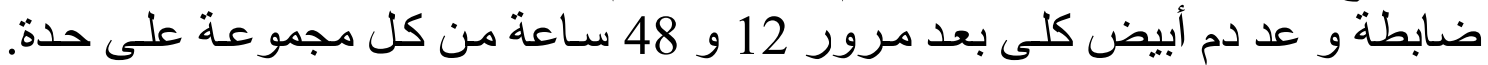

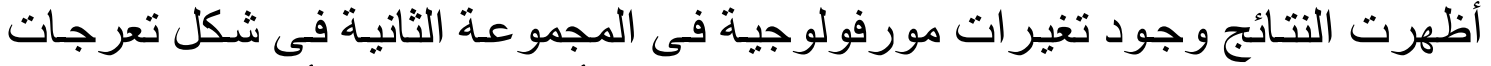

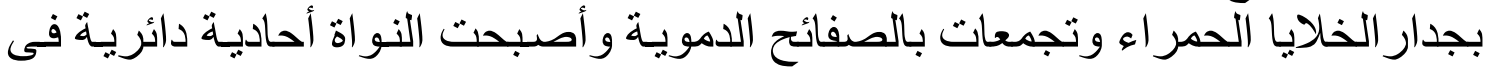

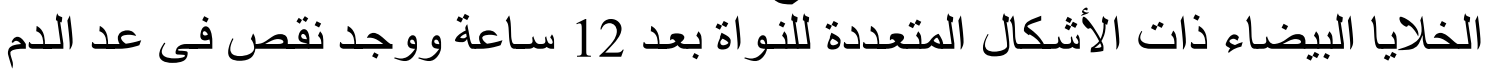

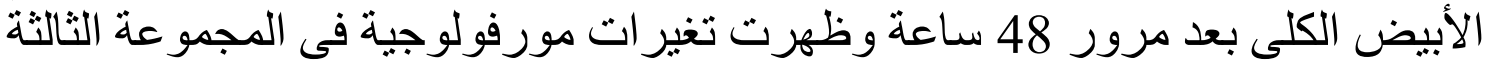

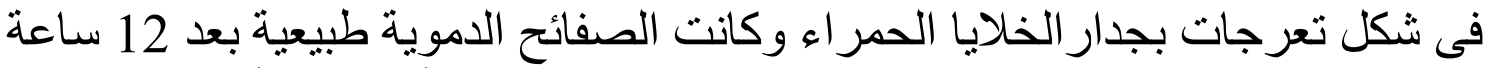

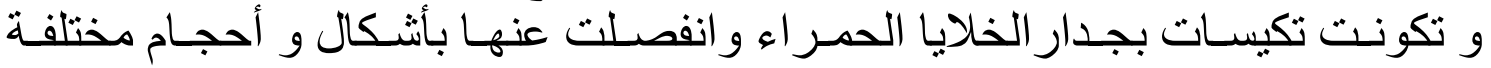

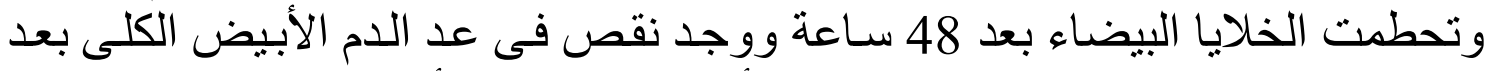

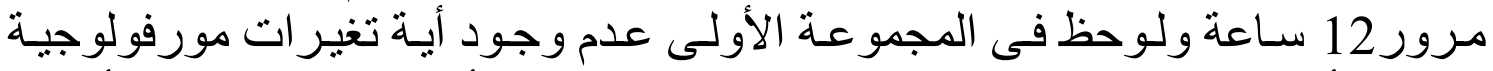

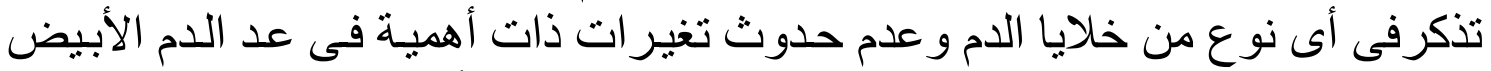

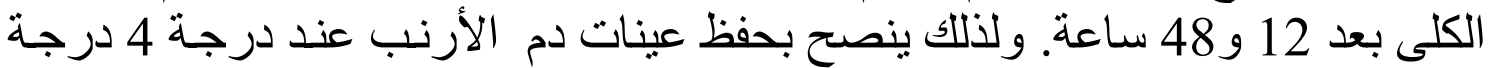

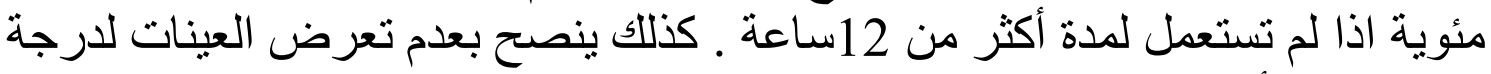

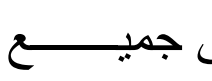
ف رارة الغرف بن $\ddot{a}$

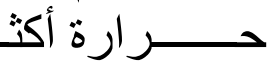

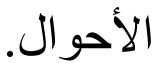

